\title{
The Clinical Application of a Positive
} Intervention Program in Patients Who Experienced a Cardiovascular Operation -Pilot Study

\author{
Konstantinos Kanellakis, Anna Papadimitriou, Eirini Karakasidou, Anastassios Stalikas \\ Department of Psychology, Panteion University, Athens, Greece \\ Email: irenekarakasidou@yahoo.com
}

How to cite this paper: Kanellakis, K., Papadimitriou, A., Karakasidou, E., \& Stalikas, A. (2022). The Clinical Application of a Positive Intervention Program in Patients Who Experienced a Cardiovascular Operation-Pilot Study. Psychology, 13, 27-40. https://doi.org/10.4236/psych.2022.131002

Received: December 6, 2021

Accepted: January 15, 2022

Published: January 18, 2022

Copyright $\odot 2022$ by author(s) and Scientific Research Publishing Inc. This work is licensed under the Creative Commons Attribution International License (CC BY 4.0).

http://creativecommons.org/licenses/by/4.0/

\begin{abstract}
The study aims to evaluate PEACE's effectiveness, a program that teaches positive emotions in patients after open-heart surgery. The sample consists of 15 patients ( 9 in the intervention group, 6 in the control group) aged 45 to 75. The results indicated a statistically significant improvement in anxiety, depression, negative affect and life satisfaction in the intervention group. However, there were no differences for stress and positive emotions in post measures. The control group had no statistically significant changes. Also, the intervention group was superior to the control group in the post-measurements on all the variables, except for the positive emotions. Health and mental health professionals should attend PEACE (Positive Emotions after Acute Cardiac Events) training in order to offer overall caring to patients suffering from cardiac problems.
\end{abstract}

Keywords

PEACE, Cardiovascular Operations, PPIS, Heart Problems

\section{Introduction}

In the field of Public Health, Positive Psychology Interventions (PPIs) are becoming more and more interesting, as the research background has shown that positive emotions can act protectively and benefit patients suffering from a disease. The emphasis on studying positive emotions arose, as research has shown that negative emotions, including anger, suspicion and depression, are associated with health problems, including heart problems. Specifically, negative emotions 
accelerate the heart problems onset, hamper the chances of coping and increase the recurrence rate (Nicholson et al., 2006; Rugulies, 2002). Not only negative emotions but also positive emotions seem to have a connection with health too. It was found that the lack of happiness has also been associated with health problems and mortality (Steptoe, 2019).

In contrast, the positive components show the opposite results, and they have a protective role against illnesses and mortality. For example, subjective wellbeing has been found to be associated with low rates of comorbidity and mortality (Lyubomirsky et al., 2005). Consistent with the above results, another study also found that positive emotions are positively associated with longevity and negatively with morbidity (Pressman \& Cohen, 2005).

Even if positive emotions are associated with good health, the interaction between positive emotions and physical health is complex, and its direction is often unclear. In order to clarify positive emotions' contribution, experimental, ambulatory and longitudinal methodological approaches are applied. In experimental studies, the direct effect of positive emotions on cardiac indicators is checked while the person is experiencing positive emotions. In ambulatory studies, heart rate fluctuations are recorded in cardiac indicators throughout a day or even a week. Longitudinal studies have a longer duration and examine whether high-degree positive emotions ultimately predict the prevention or improvement of heart function (Howell et al., 2007). Based on Broaden and Build theory of positive emotions by Fredrickson (2004), research has been conducted to test the effect of positive and negative emotions on heart function. Fredrickson \& Levenson (1998) conducted a survey where the participants were put to watch a movie with negative content (e.g. thriller), and the negative emotional arousal was recorded at the same time. In the next step, the participants were exposed to different kinds of movies in order to check the duration of time needed for the cardiac function to return to normal levels. The results showed that funny and pleasant movies, which evoke positive emotions, accelerated the restoration of myocardial function in relation to movies with negative or neutral content. So it seems that even neutral content is not sufficient enough to accelerate the myocardial function restoration.

We conclude that positive emotions have a beneficial impact on cardiac function. Nevertheless, are they both effective in situations of heart suffering? Previous studies supported that the patients who suffer from a physical disease, their mental health are negatively influenced too. For example, studies have shown that patients with heart problems have high rates of anxiety and suffer from depressive disorders (Castillo-Mayén et al., 2021; Chamberlain et al., 2011; Davies et al., 2004; Lemay et al., 2019; Ostir et al., 2001). Especially, older adults with heart problems have greater scores than younger adults (Everson et al., 1998). Although negative emotions are associated with health problems, it should be noted that the absence of positive emotions has the same effect too. Lack of positive emotions and well-being is associated with myocardial infarction (Ostir 
et al., 2001) and higher mortality (Blazer \& Hybels, 2004; Whittington \& Huppert, 1998).

On the other hand, the positive components have a protective effect. Ostir and his partners (Ostir et al., 2001) found in their study that positive emotions are negatively associated with the likelihood of myocardial infarction. Also, in another study, which involved patients with heart disease, the results indicated that those who scored higher in positive emotions had fewer mortality possibilities (Scherer \& Hermann-Lingen, 2009). Also, a study conducted in individuals with coronary heart disease showed that those who adopted a more optimistic explanatory style had a lower risk of developing coronary heart disease than those who were more pessimistic (Kubzansky et al., 2001). In the same direction, Davidson et al. (2010) found in their preliminary research that positive emotions had a protective role and acted preventively in the coronary heart disease onset.

In addition, well-being contributes to the optimal functioning of the individual's physiology and protects it from disease, offering a better quality of life and longevity (Singer \& Ryff, 2001). Emotional vitality (which refers to a person's sense of excitement and energy (Davis, 2009)) has positive outcomes too. Kubzansky \& Thurston (2007) tested whether emotional vitality is associated with a reduced chance of developing coronary heart disease. Six thousand twenty-five people participated in the study over a period of 15 years, and 1141 cases of coronary heart disease were officially recorded. From these incidents, it appeared that participants who scored high on emotional vitality were less likely to have a coronary heart attack. The model also included health behaviours to clarify whether the results were due to health behaviours or emotional vitality. The results eventually showed that the correlation between emotional vitality and coronary heart disease was attenuated even when health behaviours were added to the statistical model. Finally, another positive component tested in studies is forgiveness, which is in an interpersonal conflict, it helps the individual evaluate the event as less threatening (Worthington et al., 2007). A study aimed to evaluate the contribution of forgiveness to people who had experienced betrayal from a loved one. The results showed that restoring blood pressure to normal levels was faster in people who wanted to forgive the betrayal. Blood pressure measurements were checked by various means (e.g. skin conductance, fEMG) and participants willing to forgive had lower blood pressure and pulse rate readings.

According to the World Health Organization (WHO, 2006), mental health is not just the absence of disease and psychopathology but concerns the individual's ability to be functional, to have healthy interpersonal relationships, to participate in activities and to experience satisfaction from the above. Based on this definition, PPIs enhance the positive emotions and positive components in individuals's life, helping the general population prevent health problems and the patients to deal with them. PPIs educate the patients to recognize their talents, improve their social relationships, highlight their character strengths and commit to their values (Meyers et al., 2013), helping them enhance their well-being 
(Lomas et al., 2014). According to one systematic review in patients with breast cancer, PPIs enhance hope, well-being, optimism and quality of life (CasellasGrau et al., 2014). One meta-analysis in patients with health problems showed that PPIs are associated with reduced medical anxiety (Brown et al., 2019). A study delivered in female patients with multiple sclerosis showed that the participants who completed the PPIs had a reduced score in death anxiety than those in the control group (Pahlavan \& Ahi, 2020). Furthermore, another study that delivered positive psychology skills in patients after cancer treatment had the same results (Greer et al., 2019). Finally, patients with chronic pain who participated in a PPI had significant improvements in positive and negative affect and depression and maintained the positive outcomes at the 3-month follow-up (Braunwalder et al., 2021). Regarding the PPIs application in patients suffering from heart diseases, the literature is limited. Nikrahan and his partners (Nikrahan et al., 2016) conducted a study that addressed 55 individuals with a kind of heart disease. The sample was divided into intervention $(n=44)$ and control group $(n=14)$. The intervention group took part in three interventions, where the first one focused on positive emotions, character strengths and the meaning of life (Seligman, 2002), the second on spirituality, gratitude, optimism and coping strategies (Lyubomirsky, 2008) and the last one on optimism, awareness, goal setting and organizational skills (Fordyce, 1983). After the intervention completion, which lasted six weeks, the participants completed the post and 2-months follow-up measurements. The results showed that those who participated in the intervention group experienced greater life satisfaction, hope and happiness, and the levels of depression were decreased (Nikrahan et al., 2016).

In continuation, PPIs have been applied in patients with heart problems or patients after an acute cardiac event. A study in 128 patients with acute coronary syndrome showed that participants improved the positive effect after completing the PPI, which led them to greater commitment to physical activity (Duque et al., 2019). Also, Huffman and his parters (Huffman et al., 2016) implemented an 8-week PPI pilot program in patients with the acute coronary syndrome. Upon completion of the intervention, participants experienced an increase in positive affect, while anxiety and depressive symptoms decreased. Similarly, research in cardiac patients showed that those who participated in a PPI had higher scores on positive emotions and lower cardiac symptoms than the control group (Sultan et al., 2018).

A PPI called PEACE-III was applied in patients after an acute cardiac event. Those who participated in the intervention appeared to improve well-being and strengthen their commitment to physical activities, which helped to restore better cardiac function (Celano et al., 2018).

The PPIs interventions are applied in order to enhance the positive emotions. Except the above, Huffman (Huffman et al., 2017, 2011) designed PEACE (Positive Emotions after Acute Cardiac Events), an intervention that addresses patients who had an acute cardiac event. PEACE aims to enhance the positivity in 
the specific group. Nevertheless, there are no research data that have proven its effectiveness. The present study is the first research attempt whose aim is to evaluate the effectiveness of the intervention in patients who have dealt with open heart surgery. The target group was selected, because according to previous surveys there were no PPIs interventions for the specific group. The majority of surveys were conducted on patients with cardiovascular problems (e.g. conorary heart disease), but we have no data for patients who have faced open-heart surgery. Since the specific group experience, high levels of anxiety and negative emotions, the purpose of the study is to test the program's efficacity.

The present study aims to examine the effectiveness of PEACE, an eight-week intervention program on patients who suffer from cardiovascular problems and precisely its effectiveness in increasing positive emotions.

Particularly, the current study aims to answer the following research questions:

1) Is PEACE effective in increasing life satisfaction in patients who have faced open-heart surgery?

2) Is PEACE effective in increasing positive emotions in patients who have faced open-heart surgery?

3) Is PEACE effective in decreasing negative emotions in patients who have faced open-heart surgery?

4) Is PEACE effective in decreasing depression, anxiety and stress in patients who have faced open-heart surgery?

\section{Methods}

\subsection{Participants}

In the present study, the sample comprised $N=15$ participants, of which $n=9$ participated in the intervention group and $n=6$ in the control group. Their age ranged from 45 to 75 years old. From the intervention group, $77.8 \%$ were men and $22.2 \%$ women, while $66.7 \%$ of men and $33.3 \%$ women were in the control group. They were all citizens of Athens. All participants came from two major hospitals in Athens, a military and a cardiothoracic hospital, and they had experienced open-heart surgery.

\subsection{Materials}

The participants from both groups filled out three self-report questionnaires two times: before and after the intervention. Initially, they answered short questions concerning some demographic information (gender and age).

\section{Positive And Negative Affect Schedule}

Initially, the participants filled out the Greek version of The Positive And Negative Affect Schedule (PANAS) (Daskalou \& Sigkollitou, 2012; Watson et al., 1988), which measures positive and negative emotions. PANAS consists of 20 questions, and the participants pointed the answer, which expressed them more in a 5 -point Likert scale, ranging from $1=$ very slightly or not at all to $5=\mathrm{ex}$ - 
tremely. The scale consists of two factors, the positive and negative emotions scale, with 10 questions each. For each dimension, the total score ranges from 10 to 50. A higher score indicates higher positive and negative emotions, respectively. The reliability of this research for the positive scale is $\mathrm{a}=0.834$ and $\mathrm{a}=$ 0.872 (pre and post measures), while for the negative scale is $\mathrm{a}=0.885$ and $\mathrm{a}=$ 0.924 (pre and post measures).

\section{Depression, Anxiety, Stress Scale}

In order to test anxiety and stress, DASS-21 (Lovibond \& Lovibond, 1995) was doled out in the Greek version (Lyrakos et al., 2011). It consists of 21 questions, including three subscales (anxiety, stress, depression) with seven items. The score is given on a 4-point scale Likert ranges from 0 "did not apply to me at all" to 3 "applied to me very much or most of the time". For each subscale, the total score ranges from 0 to 21 . Reliability in the current research is for depression $\mathrm{a}=$ 0.874 and $\mathrm{a}=0.934$ (pre and post measures), for anxiety $\mathrm{a}=0.866$ and $\mathrm{a}=0.912$ (pre and post measures) and stress $\mathrm{a}=0.862$ and $\mathrm{a}=0.913$ (pre and post measures).

\section{Satisfaction with Life Scale}

The Greek version of the Satisfaction with Life Scale (Stalikas \& Lakioti, 2012; Diener et al., 1985) was given to measure life satisfaction. It consisted of 5 questions, and the participants gave their answers on a 7-point scale Likert ranging from 1 = strongly disagree to 7 = strongly agree. The total scores range from 5 to 35 , and a higher score shows higher satisfaction with life. The scale showed good internal consistency in the current study $(\mathrm{a}=0.700$ and $\mathrm{a}=0.818$ pre and post measures, respectively).

\subsection{Procedure}

The researcher studied the PEACE trainer program thoroughly from Jeffery C. $\mathrm{H}$, who gave the license to use the program in the Greek population. The PEACE program has been constructed and focused specifically on patients with cardiovascular problems. As the protocol material was in the English language, the researcher used the forward-backwards translation. Two independent translators whose English were their native language participated in this procedure. Firstly, the one translator translated the protocol from the original language (English) to the intended language (Greek) and then the intended language was translated back. No inaccuracies were identified comparing the two forms.

The participants were divided into an intervention and control group in a random way. The first contact of the researcher with the participants took place at the cardiology clinic, where they were given the briefing form, the consent form, and the debriefing form when the intervention was completed. The first meeting with the intervention group took place at the cardiology clinic, while the other 7 took place remotely by telephone and lasted 15 to 30 minutes. In the first meeting, the participants were informed about the purpose of the intervention and the procedure, and they were assigned the exercise for the next time. In the 
following telephone interviews, the researcher discussed with the participants the exercise they had and at the end, gave the next exercise.

The intervention is the adaptation of the PEACE program (Positive Emotions after Acute Cardiac Events) by Professor Jeff C. Huffman. The purpose of the program is through experiential exercises to increase resilience, positivity and empowerment. The exercises focused on gratitude, optimism and kindness in relation to heart disease. The first exercise focuses on gratitude, and participants were asked to talk about three positive events in their lives. The second meeting focused on the character strengths, and the participants were asked to identify their own, choosing one, applying it during the week and recording their feelings. At the third meeting, participants were asked to write a letter of gratitude to someone who did something meaningful for them. At their fourth meeting, they were asked to complete some individual and group enjoyable and meaningful activities. At their fifth meeting, they were asked to remember and talk about an important past event they participated in and are proud of it. At their sixth meeting, they were asked to do three good actions in a short time (one day or two) and to record their feelings. In the seventh and eighth meetings, the participants were asked to choose which exercise they liked best from the intervention program and apply it to enhance positive emotions. Also, in all the meetings, the participants answered some short questions before and after the exercise. The choice of exercises was based on the mindset that they are easy, especially for the burdened patients.

\section{Results}

Statistical analyses of the raw data collected were conducted in order to testify the research questions. Firstly, we tested the assumptions for the normality of variance using the Kolmogorov-Smirnov test and the Shapiro-Wilk test. Then, we examined any statistically significant differences between the intervention and the control group on any demographic variables (gender, age) or measures at the pretest. No statistically significant differences were found $(p>0.05)$. Since there were not any statistically significant differences, this led the researchers to testify any possible differences between the two groups and to control the final results. In continuation, we examined any changes between pre and post measures in all variables for each group separately. For the intervention group, statistically significant outcomes emerged. The intervention group had a statistically significant decrease in negative emotions $t(8)=2.922, p=0.019$, anxiety $t(8)=$ 3.844, $p=0.005$ and depression $t(8)=3.830, p=0.005$, as well as an increase in life satisfaction $t(8)=-4.045, p=0.004$. Nevertheless, no statistically significant outcomes were found neither for positive emotions $t(8)=0.659, p>0.05$ ( $p=$ 0.529 ) nor for stress $t(8)=1.880, p>0.05(p=0.097)$ (Table 1$)$. As we expected, the control group showed statistically no significant outcomes for any variable between pre and post measures ( $p>0.05)$.

Additionally, we wanted to examine whether there were statistically signifi- 
cant outcomes between the two groups in all variables at posttest measures. We employed an Independent Sample T-test. The results demonstrated statistically significant changes between the two groups, where the intervention group showed greater results than the control group. Specifically, the intervention group showed greater scores in life satisfaction rather than the control group $t$ $(13)=3.108, p=0.008$. Also, the intervention group demonstrated lower scores in anxiety $t(13)=-5.060, p=0.000$, stress $t(9.830)=-2.315, p=0.044$, depression $t(13)=-6.622, p=0.000$ and negative emotions $t(5.235)=-2.587, p=$ 0.047 rather than the control group. Statistically, no significant results were found for positive emotions between the two groups $t(13)=1.313, p>0.05$. The results are cited in Table 2 .

\section{Discussion}

The study's primary goal was to examine the effectiveness of the PEACE program in patients after open-heart surgery. The study aimed to examine whether the intervention group would benefit and experience a reduction in anxiety, stress, depression, and negative emotions and increased positive emotions and life satisfaction. In order to test the effectiveness of the program, we first examined the differences in the scores of each variable between the pre and post measures in each group. Then we tested the differences between the two groups and specifically whether the participants from the intervention group were

Table 1. Pretest and Posttest mean scores in the intervention group $(N=9)$.

\begin{tabular}{ccccc}
\hline & $\begin{array}{c}\text { Pre measures } \\
\mathbf{M}(\mathrm{SD})\end{array}$ & $\begin{array}{c}\text { Post measures } \\
\mathbf{M}(\mathrm{SD})\end{array}$ & $\boldsymbol{t}$ & $\boldsymbol{p}$ \\
\hline Anxiety & $11.11(6.75)$ & $3.78(3.53)$ & 3.844 & 0.005 \\
Depression & $10.22(6.30)$ & $2.89(2.42)$ & 3.830 & 0.005 \\
Negative emotions & $21.33(8.94)$ & $12.56(1.51)$ & 2.922 & 0.019 \\
Satisfaction & $21.78(7.05)$ & $29.00(3.54)$ & -4.045 & 0.004 \\
Positive emotions & $29.89(6.60)$ & $28.89(7.99)$ & 0.659 & 0.529 \\
Stress & $10.89(5.53)$ & $6.44(6.19)$ & 1.880 & 0.097
\end{tabular}

Table 2. Posttest mean scores by group.

\begin{tabular}{ccccc}
\hline & $\begin{array}{c}\text { Intervention group } \\
\mathbf{M}(\mathrm{SD})\end{array}$ & $\begin{array}{c}\text { Control group } \\
\mathrm{M}(\mathrm{SD})\end{array}$ & $\boldsymbol{t}$ & $\boldsymbol{p}$ \\
\hline Anxiety & $3.78(3.53)$ & $12.00(2.19)$ & -5.060 & 0.000 \\
Stress & $6.44(6.19)$ & $11.50(1.76)$ & -2.315 & 0.044 \\
Depression & $2.89(2.42)$ & $11.67(2.66)$ & -6.622 & 0.000 \\
Negative emotions & $12.56(1.51)$ & $21.17(8.06)$ & -2.587 & 0.047 \\
Satisfaction & $29.00(3.54)$ & $23.17(3.60)$ & 3.108 & 0.008 \\
Positive emotions & $28.89(7.99)$ & $33.83(5.53)$ & 1.313 & 0.212 \\
\hline
\end{tabular}


benefitted more than those from the control group with no intervention.

The results demonstrated that the intervention group participants benefited from the PEACE program. There was a significant reduction in anxiety, depression, and negative emotions in the post measures, while life satisfaction increased. These findings are consistent with results from previous PPIs programs, where exercises focused on positive components such as optimism and gratitude were applied. These results are in agreement with previous studies in patients with heart problems since the participation in a PPI has benefited them, as they have seen an increase in life satisfaction (Nikrahan et al., 2016) and a decrease in depressive symptoms (Huffman et al., 2016; Nikrahan et al., 2016). Participation in a PPI also helps reduce depression and chronic pain (Braunwalder et al., 2021). Furthermore, the effectiveness of the intervention in the symptoms of anxiety agrees with previous studies in patients with heart problems (Huffman et al., 2016) and patients with various health problems (Brown et al., 2019; Greer et al., 2019; Pahlavan \& Ahi, 2020). Patients with health problems often experience anxiety and depression (Castillo-Mayén et al., 2021; Chamberlain et al., 2011; Davies et al., 2004; Lemay et al., 2019; Ostir et al., 2001). Therefore, practising new skills, which cultivate gratitude, gaining a more optimistic perspective and recognizing their character strengths help them manage stress and depressive symptoms better.

In continuation, the participants in the intervention group noted a reduction in negative emotions, which was superior to the control group. Although there are no data in the previous literature on patients with heart problems, it has been shown that the patients with chronic pain who participated in a PPI had a lower score on negative emotions. The effect was maintained three months later (Braunwalder et al., 2021).

However, it should be noted that no statistically significant differences in stress and positive emotions were observed between the pre and post measures. According to previous PPIs, positive affect was expected to increase (Duque et al., 2019; Huffman et al., 2016; Sultan et al., 2018), but no similar findings were observed. While there was a decrease in negative emotions, there was no corresponding increase in positive ones. The reduction of negative emotions does not automatically lead to an increase of positive ones (Diener \& Emmons, 1984). Also, it needs to mention that in the pre measures, the mean of positive emotions was above average, so this probably explains why there was no statistically significant difference. Finally, it is essential to note that attending an intervention program does not automatically mean reinforcing positive emotions, as in order to experience positive emotions, the individual needs to experience a series of positive experiences of longer duration and stability. Also, the positive emotions (e.g. excited, interested) compared to negative ones (e.g. shame, fear, anger) are not easily discernible and often recognizable (Fredrickson, 2003), and this may influence participants' responses.

Although 4 points reduced the stress average in the post measures, this dif- 
ference was not statistically significant. One possible explanation is that the participants through the PEACE exercises changed the interpretation, the appraisal and the attribution of the negative situations, while the stress referring to a physiological reaction (Chrousos \& Gold, 1992) was not changed.

\section{Implications}

Overall, it seems that the PEACE intervention program is effective and benefits a patient after experiencing open-heart surgery. Commitment to exercises that cultivate kindness, gratitude, optimism about the experience of heart problems, and the recognition of the character strengths helps manage stress better, reduce depressive symptoms and negative emotions, and increase life satisfaction despite the adverse event. People experiencing open heart surgery are called to manage various changes, so it is necessary to adapt their lifestyle, and PEACE can motivate them to ameliorate their quality of life.

\section{Limitations and Future Research Directions}

One limitation is that the intervention's effectiveness was based only on post measures after the completion. There were no follow-up measures to evaluate the long-term benefits. Also, a limitation concerns the demographic characteristics of the sample, which may influence the final results. Initially, men were overrepresented in both groups, the participants' age ranged from 45 to 75, and they were all citizens of Athens. In the end, the sample was collected exclusively from two hospitals in Athens.

Future directions should focus on the long-term of the PEACE program in order to have a more overall appraisal of its effectiveness. Since PEACE seems to be effective for patients after open-heart surgery, it enhances life satisfaction and reduces anxiety, depression, and negative affect. It is vital to address a bigger number of patients with cardiac problems and be part of it caring in hospitals. Finally, since it was the first attempt in the Greek population, a training course in PEACE is essential for health (e.g. medical and nursing staff) and mental health (e.g. health psychologists) professionals to help more and more people after open heart surgery. Whether health and mental health professionals take part in the training program, they may build a strong relationship with the patients after the open-heart surgery and the latter will experience the program's benefits. Then, they may live a more productive life, experiencing life satisfaction and managing negative emotions, stress, anxiety and depression and finally, they may manage to build a new ordinary life after the adverse event. The PEACE does not only focus on the adverse event, but through the exercises, the patients cultivate kindness and gratitude and they recognize their character strengths. So, the PEACR program will not only help the patients to manage the negative emotions, but also experience life satisfaction, which will lead them to organize their daily routine in a more positive way. 


\section{Conflicts of Interest}

The authors declare no conflicts of interest regarding the publication of this paper.

\section{References}

Blazer, D. G., \& Hybels, C. F. (2004). What Symptoms of Depression Predict Mortality in Community-Dwelling Elders? Journal of the American Geriatrics Society, 52, 2052-2056. https://doi.org/10.1111/j.1532-5415.2004.52564.x

Braunwalder, C., Müller, R., Glisic, M., \& Fekete, C. (2021). Are Positive Psychology Interventions Efficacious in Chronic Pain Treatment? A Systematic Review and MetaAnalysis of Randomized Controlled Trials. Pain Medicine, 23, 122-136. https://doi.org/10.1093/pm/pnab247

Brown, L., Ospina, J. P., Celano, C. M., \& Huffman, J. C. (2019). The Effects of Positive Psychological Interventions on Medical Patients' Anxiety: A Meta-Analysis. Psychosomatic Medicine, 81, 595-602. https://doi.org/10.1097/PSY.0000000000000722

Casellas-Grau, A., Font, A., \& Vives, J. (2014). Positive Psychology Interventions in Breast Cancer. A Systematic Review. Psycho-Oncology, 23, 9-19. https://doi.org/10.1002/pon.3353

Castillo-Mayén, R., Luque, B., Gutiérrez-Domingo, T., Cuadrado, E., Arenas, A., Rubio, S. et al. (2021). Emotion Regulation in Patients with Cardiovascular Disease: Development and Validation of the Stress and Anxiety Regulation Strategies Scale (Starts). Anxiety, Stress, \& Coping, 34, 349-364. https://doi.org/10.1080/10615806.2020.1866173

Celano, C. M., Albanese, A. M., Millstein, R. A., Mastromauro, C. A., Chung, W. J., Campbell, K. A. et al. (2018). Optimizing a Positive Psychology Intervention to Promote Health Behaviors Following an Acute Coronary Syndrome: The Positive Emotions after Acute Coronary Events-III (PEACE-III) Randomized Factorial Trial. Psychosomatic Medicine, 80, 526-534. https://doi.org/10.1097/PSY.0000000000000584

Chamberlain, A. M., Vickers, K. S., Colligan, R. C., Weston, S. A., Rummans, T. A., \& Roger, V. L. (2011). Associations of Preexisting Depression and Anxiety with Hospitalization in Patients with Cardiovascular Disease. Mayo Clinic Proceedings, 86, 1056-1062. https://doi.org/10.4065/mcp.2011.0148

Chrousos, G. P., \& Gold, P. W. (1992). The Concepts of Stress and Stress System Disorders: Overview of Physical and Behavioral Homeostasis. JAMA, 267, 1244-1252. https://doi.org/10.1001/jama.1992.03480090092034

Daskalou, \& Sigkollitou (2012). Positive and Negative Affect Scale (PANAS). In A. Stalikas, S. Triliva, \& P. Roussi (Eds.), Psychometric Instruments in Greece (2nd ed., p. 526). Pedio.

Davidson, K. W., Mostofsky, E., \& Whang, W. (2010). Don't Worry, Be Happy: Positive Affect and Reduced 10-Year Incident Coronary Heart Disease: The Canadian Nova Scotia Health Survey. European Heart Journal, 31, 1065-1070.

https://doi.org/10.1093/eurheartj/ehp603

Davies, S. J., Jackson, P. R., Potokar, J., \& Nutt, D. J. (2004). Treatment of Anxiety and Depressive Disorders in Patients with Cardiovascular Disease. BMJ, 328, 939-943. https://doi.org/10.1136/bmj.328.7445.939

Davis, M. C. (2009). Building Emotional Resilience to Promote Health. American Journal of Lifestyle Medicine, 3, 60S-63S. https://doi.org/10.1177/1559827609335152

Diener, E. D., Emmons, R. A., Larsen, R. J., \& Griffin, S. (1985). The Satisfaction with Life 
Scale. Journal of Personality Assessment, 49, 71-75.

https://doi.org/10.1207/s15327752jpa4901_13

Diener, E., \& Emmons, R. A. (1984). The Independence of Positive and Negative Affect. Journal of Personality and Social Psychology, 47, 1105-1117. https://doi.org/10.1037/0022-3514.47.5.1105

Duque, L., Brown, L., Celano, C. M., Healy, B., \& Huffman, J. C. (2019). Is It Better to Cultivate Positive Affect or Optimism? Predicting Improvements in Medical Adherence Following a Positive Psychology Intervention in Patients with Acute Coronary Syndrome. General Hospital Psychiatry, 61, 125-129. https://doi.org/10.1016/j.genhosppsych.2019.06.001

Everson, S. A., Roberts, R. E., Goldberg, D. E., \& Kaplan, G. A. (1998). Depressive Symptoms and Increased Risk of Stroke Mortality over a 29-Year Period. Archieves of Internal Medicine, 158, 1133-1138. https://doi.org/10.1001/archinte.158.10.1133

Fordyce, M. (1983). A Program to Increase Happiness: Further Studies. Journal of Counseling Psychology, 30, 480-498. https://doi.org/10.1037/0022-0167.30.4.483

Fredrickson, B. L. (2003). The Value of Positive Emotions: The Emerging Science of Positive Psychology Is Coming to Understand Why It's Good to Feel Good. American Scientist, 91, 330-335. https://doi.org/10.1511/2003.4.330

Fredrickson, B. L., \& Levenson, R. W. (1998). Positive Emotions Speed Recovery from the Cardiovascular Sequelae of Negative Emotions. Cognition and Emotion, 12, 191-220. https://doi.org/10.1080/026999398379718

Greer, S., Ramo, D., Chang, Y. J., Fu, M., Moskowitz, J., \& Haritatos, J. (2019). Use of the Chatbot "Vivibot" to Deliver Positive Psychology Skills and Promote Well-Being among Young People after Cancer Treatment: Randomized Controlled Feasibility Trial. JMIR mHealth and uHealth, 7, Article ID: e15018. https://doi.org/10.2196/15018

Howell, R. T., Kern, M. L., \& Lyubomirsky, S. (2007). Health Benefits: Meta-Analytically Determining the Impact of Well-Being on Objective Health Outcomes. Health Psychology Review, 1, 83-136. https://doi.org/10.1080/17437190701492486

Huffman, J. C., Albanese, A. M., Campbell, K. A., Celano, C. M., Millstein, R. A., Mastromauro, C. A. et al. (2017). The Positive Emotions after Acute Coronary Events Behavioral Health Intervention: Design, Rationale, and Preliminary Feasibility of a Factorial Design Study. Clinical trials, 14, 128-139. https://doi.org/10.1177/1740774516673365

Huffman, J. C., Mastromauro, C. A., Boehm, J. K., Seabrook, R., Fricchione, G. L., Denninger, J. W., \& Lyubomirsky, S. (2011). Development of a Positive Psychology Intervention for Patients with Acute Cardiovascular Disease. Heart international, 6, Article No. e14.

Huffman, J. C., Millstein, R. A., Mastromauro, C. A., Moore, S. V., Celano, C. M., Bedoya, C. A. et al. (2016). A Positive Psychology Intervention for Patients with an Acute Coronary Syndrome: Treatment Development and Proof-of-Concept Trial. Journal of Happiness Studies, 17, 1985-2006. https://doi.org/10.1007/s10902-015-9681-1

Fredrickson, B. L. (2004). The Broaden-and-Build Theory of Positive Emotions. Philosophical Transactions of the Royal Society of London. Series B: Biological Sciences, 359, 13671377. https://doi.org/10.1098/rstb.2004.1512

Kubzansky, L. D., \& Thurston, R. C. (2007). Emotional Vitality and Incident Coronary Heart Disease: Benefits of Healthy Psychological Functioning. Archives of General Psychiatry, 64, 1393-1401. https://doi.org/10.1001/archpsyc.64.12.1393

Kubzansky, L. D., Sparrow, D., Vokonas, P., \& Kawachi, I. (2001). Is the Glass Half Empty or Half Full? A Prospective Study of Optimism and Coronary Heart Disease in the 
Normative Aging Study. Psychosomatic Medicine, 63, 910-916. https://doi.org/10.1097/00006842-200111000-00009

Lemay, K. R., Tulloch, H. E., Pipe, A. L., \& Reed, J. L. (2019). Establishing the Minimal Clinically Important Difference for the Hospital Anxiety and Depression Scale in Patients with Cardiovascular Disease. Journal of Cardiopulmonary Rehabilitation and Prevention, 39, E6-E11. https://doi.org/10.1097/HCR.0000000000000379

Lomas, T., Hefferon, K., \& Ivtzan, I. (2014). Applied Positive Psychology: Integrated Positive Practice. Sage. https://doi.org/10.4135/9781473909687

Lovibond, P. F., \& Lovibond, S. H. (1995). The Structure of Negative Emotional States: Comparison of the Depression Anxiety Stress Scales (DASS) with the Beck Depression and Anxiety Inventories. Behaviour Research and Therapy, 33, 335-343. https://doi.org/10.1016/0005-7967(94)00075-U

Lyrakos, N. G., Arvaniti, C., Smyrnioti, M., \& Kostopanagiotou, G. (2011). Translation and Validation study of the Depression Anxiety Stress Scale in the Greek General Population and in a Psychiatric Patient's Sample. European Psychiatry, 26, 1731. https://doi.org/10.1016/S0924-9338(11)73435-6

Lyubomirsky, S. (2008). The How of Happiness: A Scientific Approach to Getting the Life you Want. Penguin.

Lyubomirsky, S., King, L. A., \& Diener, E. (2005). The Benefits of Frequent Positive Affect: Does Happiness Lead to Success? Psychological Bulletin, 131, 803-855. https://doi.org/10.1037/0033-2909.131.6.803

Meyers, M., van Woerkom, M., \& Bakker, A. (2013). The Added Value of the Positive: A Literature Review of Positive Psychology Interventions in Organizations. European Journal of Work and Organizational Psychology, 22, 618-632. https://doi.org/10.1080/1359432X.2012.694689

Nicholson, A., Kuper, H., \& Hemingway, H. (2006). Depression as an Aetiologic and Prognostic Factor in Coronary Heart Disease: A Meta-Analysis of 6362 Events among 146538 Participants in 54 Observational Studies. European Heart Journal, 27, 2763-2774. https://doi.org/10.1093/eurheartj/ehl338

Nikrahan, G. R., Suarez, L., Asgari, K., Beach, S. R., Celano, C. M., Kalantari, M., Abedi, M. R., Etesampour, A., Abbas, R., \& Huffman, J. C. (2016). Positive Psychology Interventions for Patients with Heart Disease: A Preliminary Randomized Trial. Psychosomatics, 57, 348-358. https://doi.org/10.1016/j.psym.2016.03.003

Ostir, G. V., Markides, K. S., Peek, M. K., \& Goodwin, J. S. (2001). The Association between Emotional Well-Being and the Incidence of Stroke in Older Adults. Psychosomatic Medicine, 63, 210-215. https://doi.org/10.1097/00006842-200103000-00003

Pahlavan, A., \& Ahi, G. (2020). Effectiveness of Positive Psychology Interventions on Death Anxiety and Sleep Quality of Female Patients with Multiple Sclerosis (MS). Research in Clinical Psychology and Counseling, 9, 28-42.

Pressman, S. D., \& Cohen, S. (2005). Does Positive Affect Influence Health? Psychological Bulletin, 131, 925-971. https://doi.org/10.1037/0033-2909.131.6.925

Rugulies, R. (2002). Depression as a Predictor for Coronary Heart Disease. A Review and Meta-Analysis. American Journal of Preventive Medicine, 23, 51-61. https://doi.org/10.1016/S0749-3797(02)00439-7

Scherer, M., \& Herrmann-Lingen, C. (2009). Single Item on Positive Affect Is Associated with 1-Year Survival in Consecutive Medical Inpatients. General Hospital Psychiatry, 31, 8-13. https://doi.org/10.1016/j.genhosppsych.2008.09.020

Seligman, M. (2002). Authentic Happiness: Using the New Positive Psychology to Realize 
Your Potential for Lasting Fulfillment. Free Press.

Singer, B., \& Ryff, C. D. (2001). New Horizons in Health: An Integrative Approach. National Academy Press.

Stalikas, A., \& Lakioti, A. (2012). Satisfaction with Life Scale (SWLS). In A. Stalikas, S. Triliva, \& P. Roussi (Eds.), Psychometric Instruments in Greece (2nd ed., p. 752). Pedio.

Steptoe, A. (2019). Happiness and Health. Annual Review of Public Health, 40, 339-359. https://doi.org/10.1146/annurev-publhealth-040218-044150

Sultan, S., Fatima, S., \& Kanwal, F. (2018). Treating Heart Patients by Enhancing Positive Emotions through Positive Psychology Intervention. Pakistan Heart Journal, 51, 303-308.

Watson, D., Clark, L. A., \& Tellegen, A. (1988). Development and Validation of Brief Measures of Positive and Negative Affect: The PANAS Scales. Journal of Personality and Social Psychology, 54, 1063-1070. https://doi.org/10.1037/0022-3514.54.6.1063

Whittington, J., \& Huppert, F. A. (1998). Creating Invariant Subscales of the GHQ-30. Social Science \& Medicine, 46, 1429-1440. https://doi.org/10.1016/S0277-9536(97)10133-2

World Health Organization (WHO) (2006). Constitution of the World Health Organization. http://www.who.int/governance/eb/who_constitution_en.pdf

Worthington, E. L., Witvliet, C. V., Pietrini, P., \& Miller, A. J. (2007). Forgiveness, Health, and Well-Being: A Review of Evidence for Emotional versus Decisional Forgiveness, Dispositional Forgivingness, and Reduced Unforgiveness. Journal of Behavioral Medicine, 30, 291-302. https://doi.org/10.1007/s10865-007-9105-8 